\title{
A Novel Analog Circuit Design for Maximum Power Point Tracking of Photovoltaic Panels
}

\author{
Nesrine Mhiri, ${ }^{1}$ Abdulrahman Alahdal, ${ }^{2}$ Hamza Ghulman, ${ }^{2}$ and Anis Ammous ${ }^{1,2}$ \\ ${ }^{1}$ Power Electronics Group (PEG), National School of Engineers of Sfax, University of Sfax, Sfax, Tunisia \\ ${ }^{2}$ DEE, Umm Al Qura University, Makkah, Saudi Arabia \\ Correspondence should be addressed to Anis Ammous; aaammous@uqu.edu.sa
}

Received 7 April 2017; Revised 20 June 2017; Accepted 26 July 2017; Published 25 September 2017

Academic Editor: Mohamed Orabi

Copyright (C) 2017 Nesrine Mhiri et al. This is an open access article distributed under the Creative Commons Attribution License, which permits unrestricted use, distribution, and reproduction in any medium, provided the original work is properly cited.

\begin{abstract}
A new analog technique is proposed in order to track the maximum power point (MPP) of PV panels. The proposed technique uses the well-known simple functions of electronic circuits. The proposed technique is validated by applying it to boost based off grid PV system. The simulation of the PV system was done on the circuit oriented simulator Proteus-ISIS. A good efficiency of the analog technique (more than 98\%) was registered. The variation of irradiation was introduced in order to study the robustness of the proposed analog MPPT technique.
\end{abstract}

\section{Introduction}

Currently, the production of domestic and industrial energy is based, in large part, on a limited resource: oil. Oil sources are becoming more and more rare, while the energy demands of the world rise continually. Since this form of energy covers a large part of the current energy production, it is necessary to find another solution to take over. The imposed constraint is to use an energy source that is economical and less polluting because the protection of the environment has become an important point [1-3].

The search for alternative energy resources has therefore become a crucial issue these days. Many scientific researches have been carried out, not only in the field of nuclear energy production, but also in the sector of unlimited energy sources, such as wind power generation and energy transformation. In the latter case, the design, optimization, and realization of photovoltaic systems are topical issues since they lead to a better exploitation of solar energy [2].

These photovoltaic powers generating systems can be operated in different places: electrification of isolated sites, installation in buildings or direct connection to network of electricity, and so on.

A major problem with PV systems is to realize transfer of maximum power from PV generator to load. For several years, many MPPT control methods have been developed and implemented, like Fuzzy Logic Method [4-7], perturbation and observation $(\mathrm{P} \& \mathrm{O})$ method $[5,6,8]$, and Incremental Conductance (Inc.Con.) method [7, 9-11]. These techniques are generally complex and expensive to implement $[4,9$, 12]. They differ in several aspects like complexity, range of effectiveness, cost, convergence speed, implementation hardware, required sensors, and popularity, plus other respects. However, these techniques are digital implementation.

Alternatively, the MPPT can be implemented by analog circuits [13-15]. The potential benefit from analog solution is that the MPPT can be integrated with DC-DC controller such that "plug and play" can be expected for many low power PV applications. In fact, integration of certain functions into a normal PWM controller chip is the most desirable way for special applications to reduce the implementation complexity and system cost.

In this paper, a new analog MPPT technique suitable for PV system applications is presented and validated by simulations.

\section{Solar Cell Characteristics and PV Module}

Solar cell is the main building block of PV arrays, which consist of many photovoltaic cells linked in parallel/series manner for each module. A PV cell can be modeled from the 


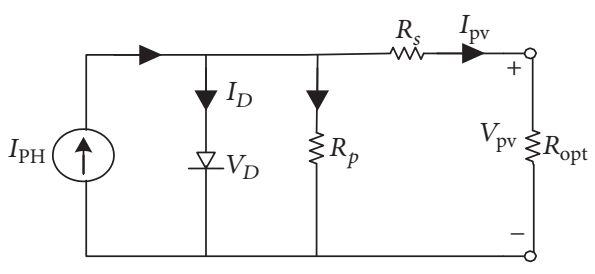

Figure 1: Equivalent circuit of solar PV cell.

equation defining the static behavior of the $\mathrm{PN}$ junction of a conventional diode. Thus, Figure 1 illustrates the electrical equivalent scheme of a real PV cell. In this equation, the short-circuit current and the various resistors modeling the losses due to the connection are taken into account. Thus, in static state, the behavior of a PV cell made up of a siliconbased PN junction can be described by $[16,17]$

$$
I_{\mathrm{pv}}=I_{\mathrm{PH}}-I_{D}-\left(\frac{V_{D}}{R_{p}}\right) .
$$

The primary solar cell equivalent circuit can involve a current source in parallel with a diode and a shunt relatively large resistance $\left(R_{p}\right)$, in addition to a usually small parasitic series resistance $\left(R_{s}\right)$. However, $R_{p}$ is mainly attributed to the $\mathrm{p}-\mathrm{n}$ junction, the nonlinearity, and impurities near the junction $[16,17]$.

The current $I_{D}$ is given by the Shockley equation:

$$
I_{D}=I_{0}\left[\operatorname{Exp}\left(\frac{q V}{n K T}\right)-1\right]
$$

where $I_{0}, q, K$, and $T$ are, respectively, the cell's reverse saturation current, the charge of electrons, Boltzmann's constant, and the cell's working temperature, $n$ is the diode ideality factor, and $V$ is the voltage across the diode terminals.

The PV module characteristic has a current boundary called short-circuit current $I_{\mathrm{sc}}=I_{\mathrm{PH}}$ and a voltage boundary called open circuit voltage $V_{\text {oc }}$ given by the following equation:

$$
V_{\mathrm{oc}}=\frac{n K T}{q}\left[\ln \left(\frac{I}{I_{0}}\right)\right] .
$$

The PV module can also be characterized by the maximum power point where the product of its voltage $\left(V_{\mathrm{mp}}\right)$ and its current $\left(I_{\mathrm{mp}}\right)$ is at its maximum value. The maximum power output is derived by finding the local maxima of the product of PV output current and voltage:

$$
\begin{aligned}
\frac{d(V * I)}{d V} & =0 \\
V_{\mathrm{mp}} & =V_{\mathrm{oc}}-\frac{K T}{q}\left[\ln \left(\frac{V_{\mathrm{mp}}}{n K T / q}+1\right)\right] .
\end{aligned}
$$

The goal for a solar direct electricity generation system or photovoltaic system is to provide high quality, reliable, and green electrical power. Usually a number of PV modules are arranged in series and/or parallel combinations to
TABLE 1: Typical electrical characteristics of a PV module, JA SOLAR.

\begin{tabular}{lc}
\hline Characteristics & Specifications \\
\hline Maximum power rating & $265 \mathrm{~W}$ \\
Open circuit voltage $\left(V_{\mathrm{oc}}\right)$ & $38.38 \mathrm{~V}$ \\
Short-circuit current $\left(I_{\mathrm{sc}}\right)$ & $8.8 \mathrm{~A}$ \\
Maximum power voltage $\left(V_{\mathrm{mp}}\right)$ & $31.24 \mathrm{~V}$ \\
Maximum power current $\left(I_{\mathrm{mp}}\right)$ & $8.48 \mathrm{~A}$ \\
\hline
\end{tabular}

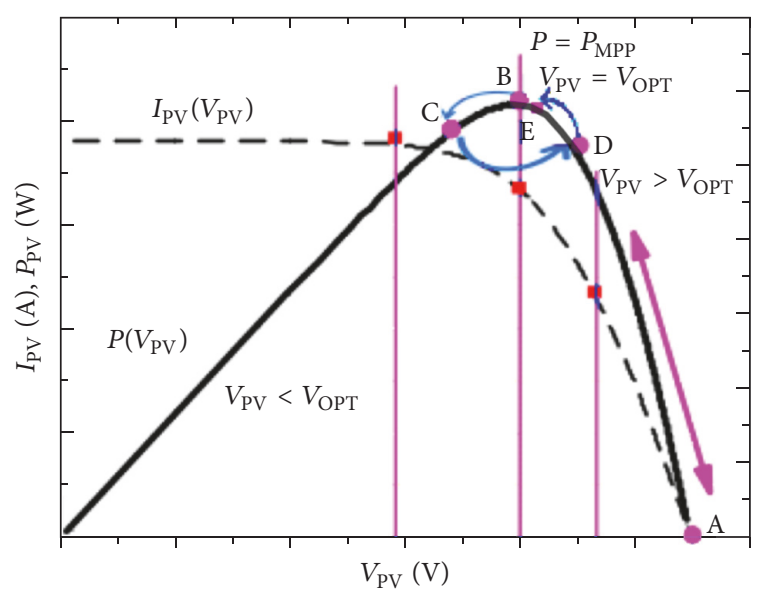

FIgURE 2: $I-V$ and $P-V$ characteristics of a solar cell showing MPP.

meet the output energy requirements. The series connection increases the module's voltage whereas the parallel connection increases its current [17].

At the temperature $25^{\circ} \mathrm{C}$ and irradiation of $1000 \mathrm{~W} / \mathrm{m}^{2}$, Table 1 shows the electrical characteristics of the used PV module given by manufacturer data sheet [18].

\section{Operation Principle of the New Analog MPPT Controller}

Maximum Power Point Tracking (MPPT) is the important factor in PV systems to maintain maximum power output. It is the component that tracks the maximum power point of the PV panel's curve.

The problem addressed by MPPT techniques is to maintain the output voltage $V_{\mathrm{MPP}}$ and current $I_{\mathrm{MPP}}$ at which a $\mathrm{PV}$ array should operate to produce the maximum power output $P_{\text {MPP }}$ under controlled conditions of irradiation and temperature.

Figure 2 shows the current-voltage $(I-V)$ and powervoltage $(P-V)$ characteristics of a typical solar cell. For overall optimal operation of the PV system, the load operating point has to match the PV array's MPP.

Here, the design of a photovoltaic system equipped with a new analog Maximum Power Point Tracking (MPPT) technique is studied. Its main parts are the switch-mode DCDC converter, the control system, and the tracking system. Proteus-ISIS simulation tool was used to show proposed analog technique performance [18]. 


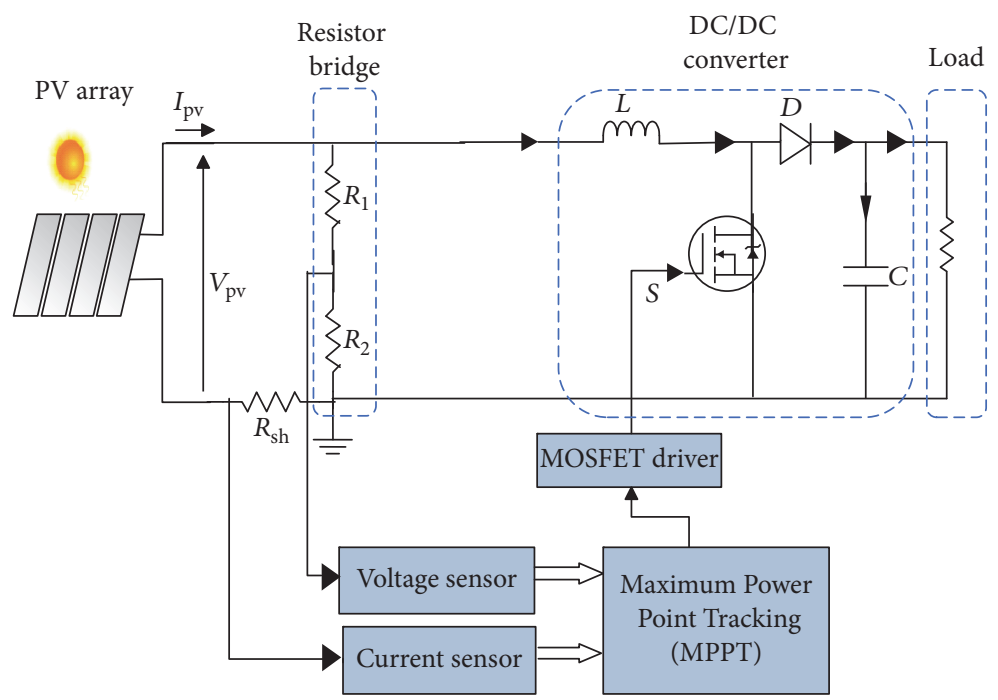

FIGURE 3: Block diagram of the proposed photovoltaic system.

3.1. Typical PV System Using Proposed Analog MPPT Controller. The two main categories of PV systems are grid tie and stand alone. In our case, we have chosen to develop the analog MPPT controller on a simple and classical stand-alone PV system. Specific equipment is required to control, transfer, distribute, and store the energy produced by the PV arrays. Figure 3 shows the basic block diagram of a typical off grid PV system that has been used in our application.

The different blocks constituting the system are as follows:

(i) The PV panels.

(ii) Load; in our case a simple impedance.

(iii) DC-DC boost power converter. In this case the output voltage is higher than the one delivered by the PV panel. The converter involves one controlled switch (Mosfet or IGBT).

The semiconductor device controlled by a variable frequency and duty cycle $(\alpha)$ driving signal.

(iv) Analog MPPT controller. It allows the track of the maximal power point of the PV array, which depends on climate conditions [19]. Consequently, the controller guides the power point of the PV panel to converge to its maximum. Its operating principle is based on the automatic variation of the duty cyclic $(\alpha)$ to continuously maximize the power at the PV array output.

The detailed diagram of the photovoltaic technique is presented in Figure 4. This controller uses the voltage and current of photovoltaic panels to calculate the instantaneous power delivered by panels.

(i) A shunt resistor $\left(R_{\mathrm{sh}}\right)$ is used as a current sensor of the PV panel.

(ii) A voltage divider composed by two resistors " $R_{1}$ and $R_{2}$ ” used to obtain an image of the voltage across PV panels. (iii) An analog multiplier is used to calculate the instantaneous output power delivered by the PV panels.

(iv) The block $P_{\text {ref }}$ generator produces a reference signal that represents the reference power. This signal has a constant magnitude, adjustable period $T_{s}$, and constant $T_{\text {off }}$ (few milliseconds). The slope rates values of the $P_{\text {ref }}$ waveform can be modified depending on system response time (Figure 7). The generator function is based on NE555 integrated circuit.

(v) Comparator (2) compares the really generated power $\left(P_{\text {real }}\right)$ and the reference power signal $\left(P_{\text {ref }}\right)$.

(vi) Hysteresis (2) is used to detect the maximum power point and to control the hold circuit, its output commutes to $(+15 \mathrm{~V})$ when the comparator (2) output reaches $\varepsilon 3$ indicating the failover of the panels operating point to the left side of the $P(V)$ characteristic (point C in Figure 2).

(vii) A hold circuit can block the value of the reference signal $\left(P_{\text {ref }}\right)$ and gives $P_{\text {blocked }}$ signal. The blocked value is slightly higher than the MPP of the panels arrays. When $P_{\text {ref }}$ is blocked, the panel operating point is in (C).

(viii) An RC cell generates a pulse when the maximum power is reached (define the values of $\Delta V 2$ and $(\Delta V 1$ $+\varepsilon 3$ ) of the generated power shown in Figure 7).

(ix) The summation block produces $P_{\text {generated }}$ from $P_{\text {blocked }}$ and the RC circuit outputs. This block output allows bringing the panel operating point from (C) to (D) and to obtain, in the steady state, the optimal value of the power detected by our technique (point $\mathrm{E}$ in Figure 2).

(x) Comparator (1) calculates the difference between $P_{\text {real }}$ and $P_{\text {generated }}$ signals.

(xi) Hysteresis (1) is used to control the real power $P_{\text {real }}$ close to the generated power waveform $P_{\text {generated }}$ which is considered as the optimal power of the 


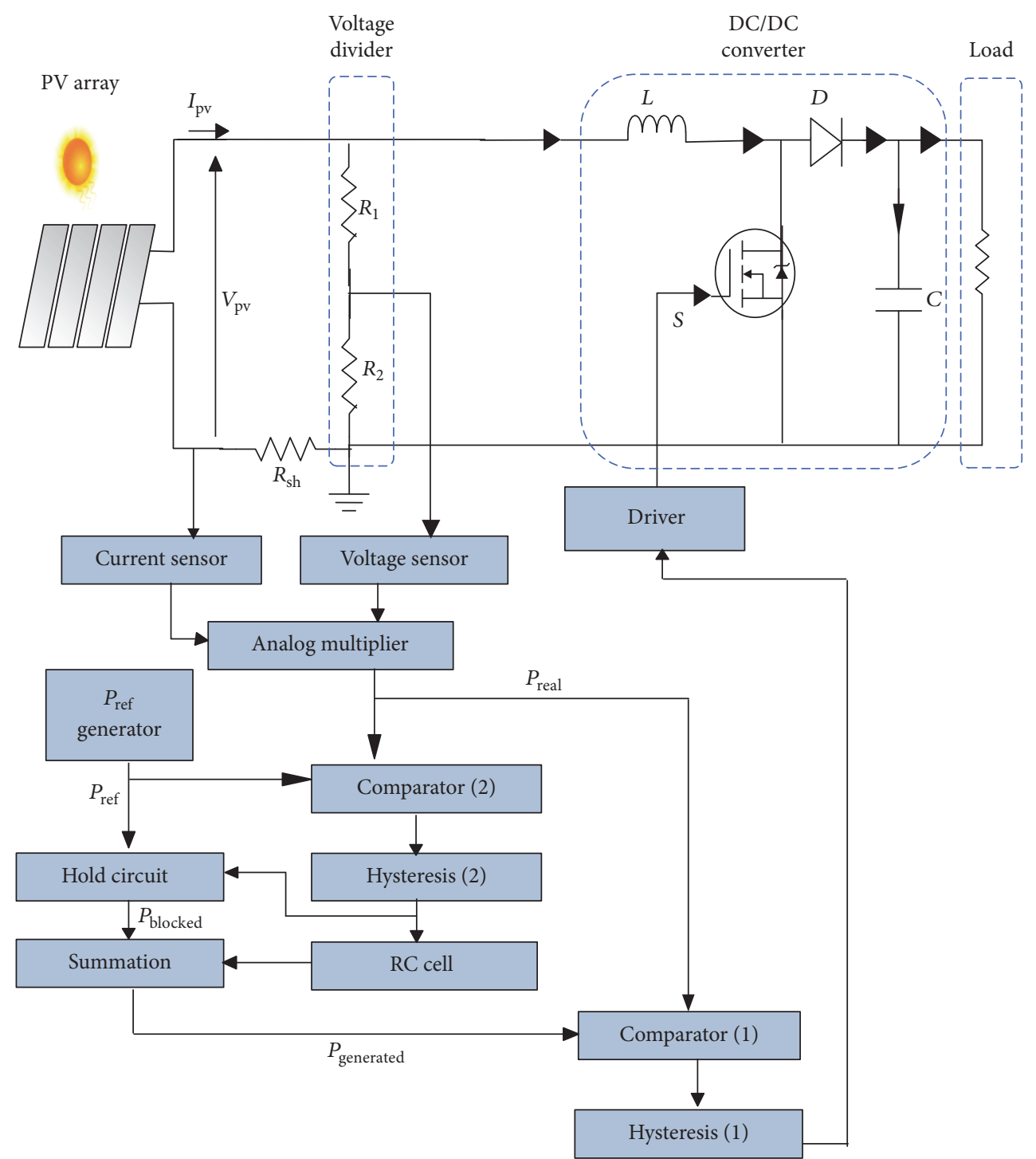

Figure 4: The detailed synoptic diagram of the whole photovoltaic technique.

PV panel deduced from our technique. If the difference between the real and generated power reaches the upper/lower limit, the power is forced to decrease/increase. The hysteresis control has the benefit of very quick response, variable switching frequency, and simpler process than other control techniques. This signal is injected to MOSFET transistor of the DC-DC boost converter through the driver.

Figure 5 shows the transfer function of hysteresis (1) and hysteresis (2) blocks.

The transfer function of hysteresis 1 block, for example, is given by the following equations:

$$
\begin{aligned}
-\varepsilon_{1} & =\frac{R_{26} V_{\text {sat }}^{-}}{R_{26}+R_{28}}, \\
\varepsilon_{2} & =\frac{R_{26} V_{\text {sat }}^{+}}{R_{26}+R_{27}} .
\end{aligned}
$$

Figure 6 shows the electrical circuit corresponding to the proposed analog MPPT technique. The circuit contains mainly one multiplier, a precision timing circuit, a hold circuit, and six operational amplifiers.

3.2. Principle of the Proposed Analog MPPT Controller. The majority of MPPT techniques attempt to vary PV current $I_{\mathrm{MPP}}$ in order to match the maximum power point or to find the PV voltage that results in the maximum power point $V_{\text {MPP. }}$.

Figure 7 shows the principle of the proposed analog technique using powers waveforms. The proposed analog technique is based on the generation of a reference power signal $\left(P_{\text {ref }}\right)$ to be followed by the PV panel's real power $\left(P_{\text {real }}\right)$ while $P_{\text {real }}$ is lower than the maximum power $P_{\max }$ (between $\mathrm{A}$ and $\mathrm{B}$ of the power static characteristic $P(V)$ ). $P_{\text {generated }}$ and $P_{\text {blocked }}$ signals are equal to $P_{\text {ref }}$ while the error between $P_{\text {ref }}$ and $P_{\text {real }}$ is within hysteresis 2 tolerance band. 


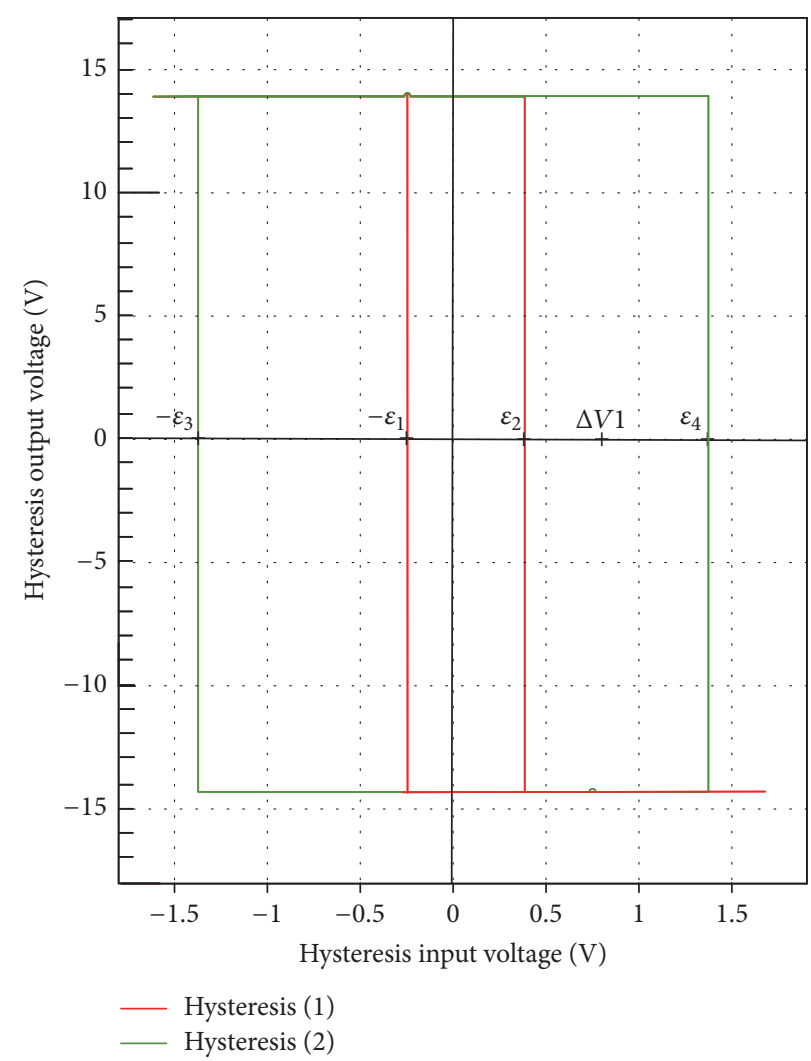

FIGURE 5: The transfer function of hysteresis (1) and hysteresis (2).

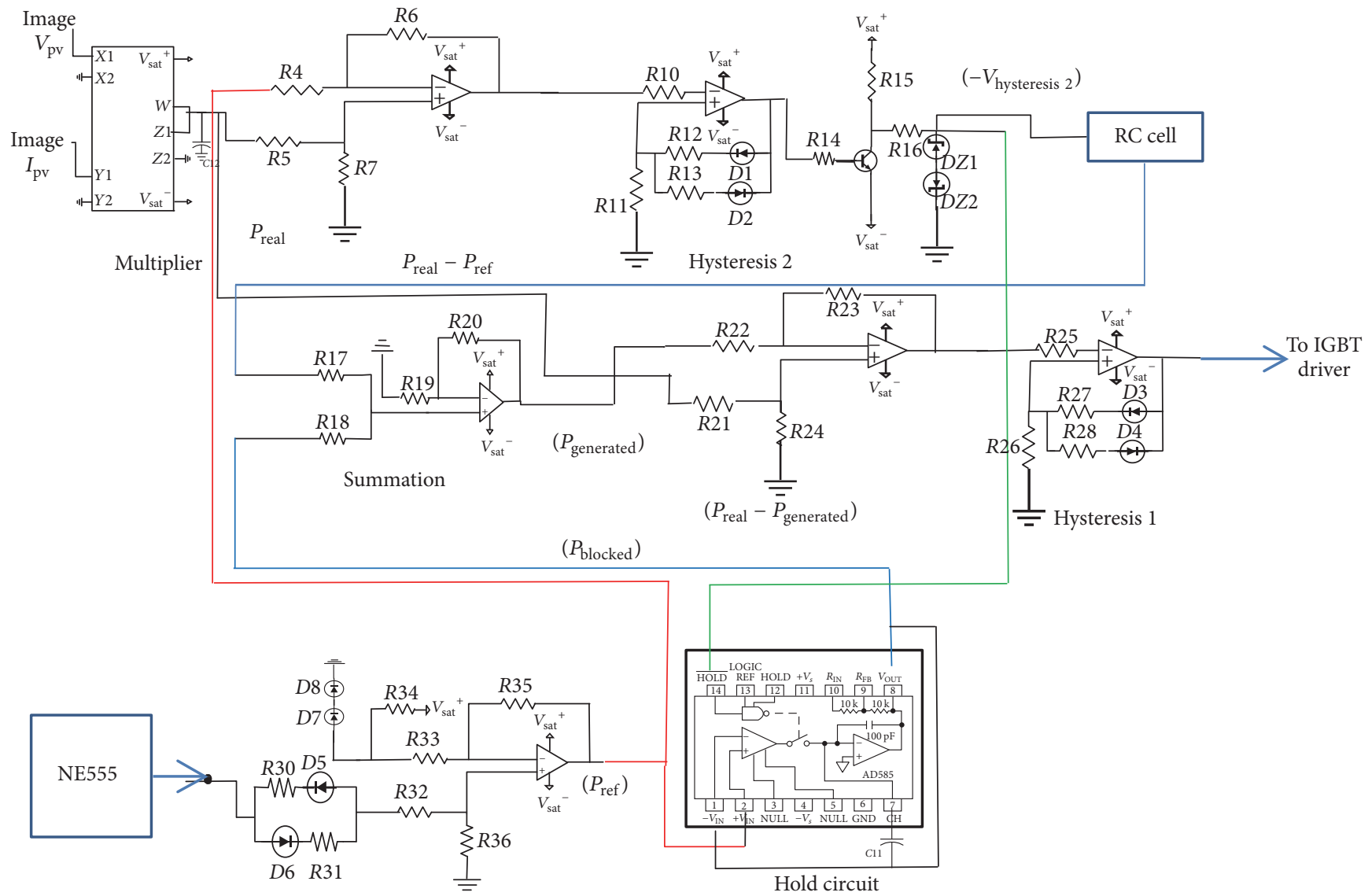

FIGURE 6: The proposed analog MPPT technique circuit. 


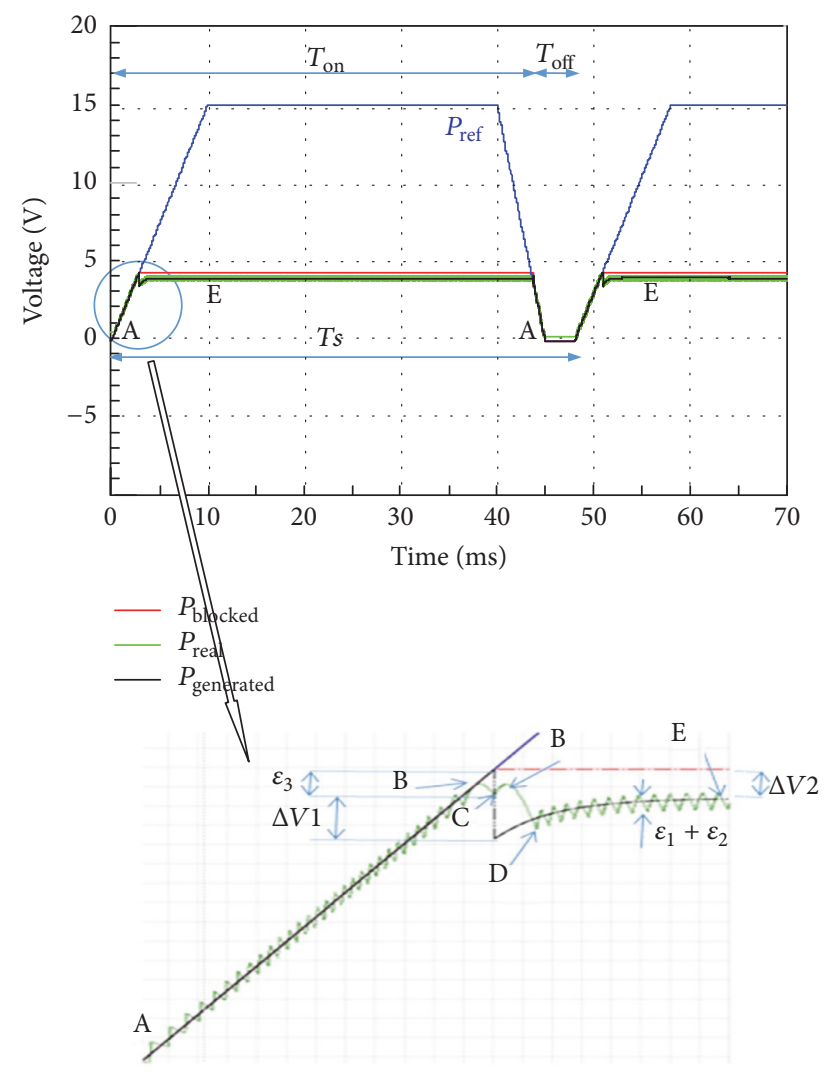

Figure 7: Different power waveforms evolutions and the corresponding panel operating point in $P(V)$ characteristic.

$P_{\text {real }}$ signal is regulated to $P_{\text {generated }}$ signal by hysteresis 1 band.

If the power magnitude is able to increase usually (from zero and initially from open circuit condition of the $P(V)$ characteristic) this means that the maximum power is not reached yet, but if, at a given moment, the power magnitude decreases this means that the maximum power was reached and a rapid blocking of the power is necessary.

When the reference signal $P_{\text {ref }}$ increases and if the actual real power could not pursue this signal (the maximum power $P_{\max }$ is reached), the panel operating point will be brought to the left side of the $P(V)$ characteristic (point $\mathrm{C}$ ). At this situation, hysteresis (2) acts on the hold circuit in order to block the $P_{\text {ref }}$ signal and obtain the signal $P_{\text {blocked }}$.

The hold circuit is just necessary to block the " $P_{\text {ref }}$ generator" block output to a constant value indicating the detection of the PV panels maximum power. The signal " $P_{\text {blocked" }}$ " is therefore generated at the output of this hold circuit.

The signal which has a variable magnitude and allows the regulation of the real power is the signal " $P_{\text {generated }}$ " issued from " $P_{\text {bloked }}$ " signal which is obtained from " $P_{\text {ref }}$ generator" block. In fact, when the detection of the maximum power was occurred by "hysteresis 2 " block, the signal issued from " $P_{\text {ref }}$ generator" creates the signal " $P_{\text {bloked. }}$ " The " $P_{\text {bloked }}$ " signal will have a variable magnitude depending on irradiation value. The signal " $P_{\text {bloked" }}$ " takes the same dynamic proprieties from the " $P_{\text {ref }}$ generator" block output but with different variable magnitude.

In the above situation, the real power cannot be regulated to the blocked value which is slightly higher than the maximum power $P_{\max }$ and the panel operating point will decrease to zero of the left side of the $P(V)$ characteristic (the increase of boost duty cycle decreases power in the left side of the $P(V)$ characteristic).

In order to avoid the above behavior of the operating point, the $P_{\text {generated }}$ signal is created in order to regulate real power to this signal in the rest of the time $T_{\text {on }}$. In fact, the panel operating point should be brought, from point $(\mathrm{C})$, to the right side of the $P(V)$ characteristic (point D). A firstorder pulse (generated by the RC cell block) is declined from the blocked signal $P_{\text {blocked }}$ and $P_{\text {generated }}$ signal is therefore obtained. Since the $P_{\text {real }}$ signal is regulated to the $P_{\text {generated }}$ signal by hysteresis (1), the panel operating point goes within its tolerance band (point D). During this transition, the operating point passes by the maximum power value (B).

The regulated real power pursues $P_{\text {generated }}$ until the operating point (E) which is slightly lower than the maximum value $P_{\max }$.

The hysteresis bands and first-order pulse magnitude are chosen so that the operating point $(\mathrm{E})$ is below the operating point (B) in the right side of the $P(V)$ characteristic.

At the end of $\left(T_{\text {on }}\right)$ and when the $P_{\text {ref }}$ signal decreases and becomes lower than actual power $P_{\text {real }}\left(\varepsilon_{4}\right.$ is exceeded), hysteresis 2 reacts and cancels the hold block control signal, $P_{\text {generated }}$ and $P_{\text {blocked }}$ signals become equal to the reference signal, and the regulated actual power $P_{\text {real }}$ decreases too and reaches the operating point $(\mathrm{A})$. The initialisation phase was then started and will continue during the time $T_{\text {off }}$.

The band 1 of "hysteresis 1" block (defined by $\varepsilon 1$ and $\varepsilon 2$ ) is fixed by the user based on current ripple and modulation frequency considerations. Band 2 of "hysteresis 2" block (defined by $\varepsilon 3$ and $\varepsilon 4$ ) should be larger than band 1 . There are no special other considerations for these bands values.

The value of $\Delta V_{2}$ is fixed by the RC cell circuit and it is chosen and given by the following condition:

$$
\Delta V_{2}-\varepsilon_{2}>\varepsilon_{3} .
$$

This condition is necessary to be sure that the operating point of the PV panels is kept in the right side of the maximum point of the $P(V)$ characteristic.

The used circuit of the RC cell block is given by Figure 8 . The input signal of this circuit is the inverse signal $\left(-V_{\text {Hysteresis 2 }}\right)$ of hysteresis 2 block output.

3.3. Simulation Results. The proposed MPPT technique, power converter, and PV arrays models are implemented in the Proteus-ISIS circuit oriented simulator. For different irradiance conditions, the different voltage waveforms corresponding to the above-mentioned power are registered and shown in Figure 9. It is clear that the real power converges, during the steady state, to a value (E) slightly lower than the array maximum power (B). The difference between the generated real power and the optimal panel power contributes to the performance assessment of the proposed analog technique. 


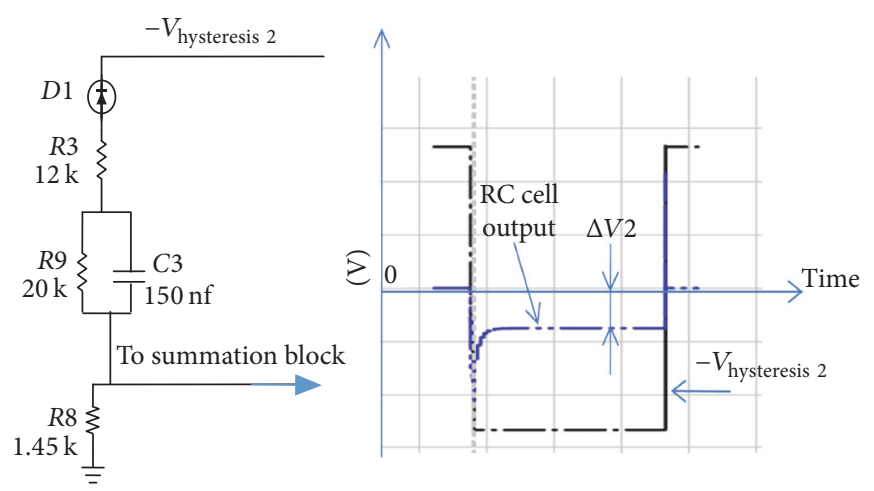

FIGURE 8: The RC cell block circuit and its output voltage waveform.

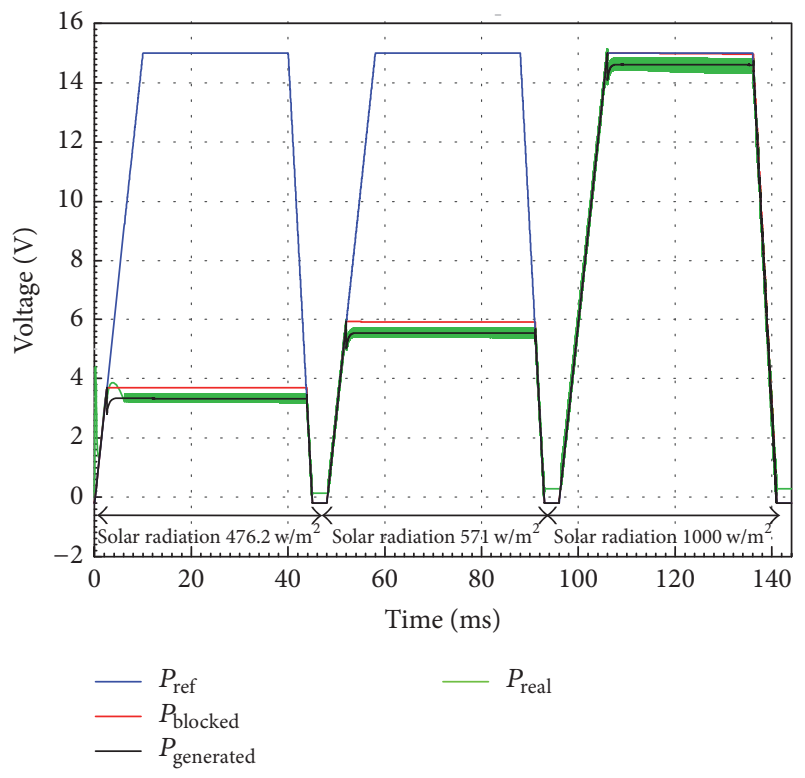

FIGURE 9: Tracked maximum power under variable solar radiation.

Figure 10 shows the evolution of the $I_{\mathrm{pv}}$ current and $V_{\mathrm{pv}}$ voltage images during one cycle of $P_{\text {ref }}$ signal.

The efficiency of the proposed MPPT technique was computed for different $T_{\text {on }}$ values. Figure 11 shows the evolutions of this efficiency as a function of radiation intensity for two $T_{\text {on }}$ values $\left(T_{\text {off }}=4 \mathrm{~ms}\right.$ ). The efficiency was calculated by the following equation:

$$
\eta=\frac{\int_{0}^{T s} P_{\text {real }}}{\int_{0}^{T s} \mathrm{MPP}} .
$$

We notice that in the input of the boost converter there is no filtering capacitance added and this in order to control instantaneously the real current in PV panels. This is considered as an advantage of the proposed MPPT technique. The choice of the value of storage inductance of the boost and hysteresis 1 band defines the variable switching frequency

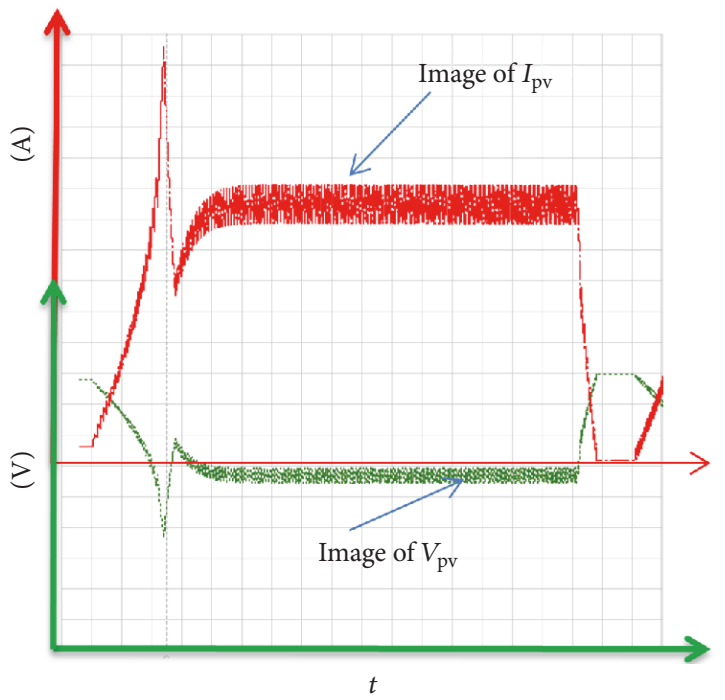

FIGURE 10: Image of the PV panels current and voltage.

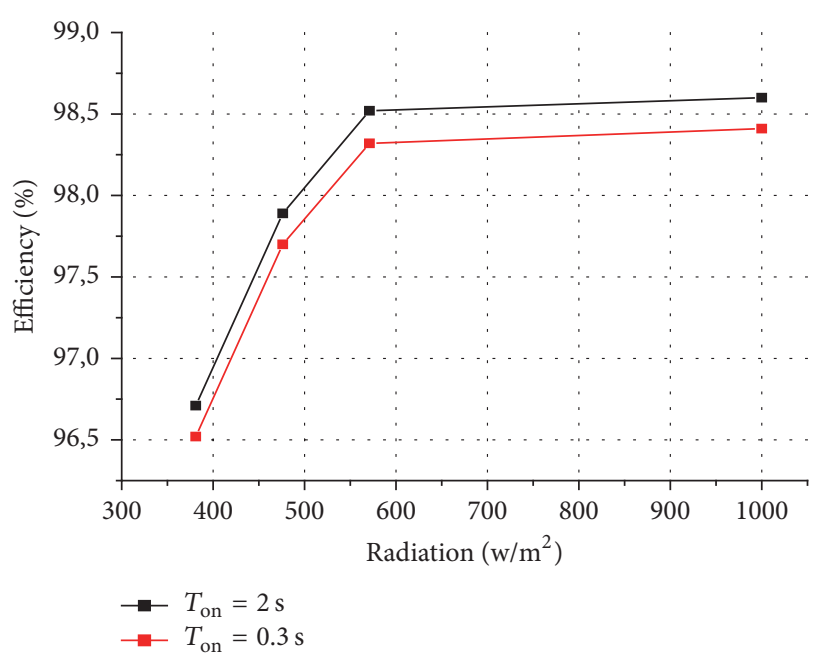

FIgURE 11: New MPPT technique efficiencies for unipolar input reference $P_{\text {ref }}$. 


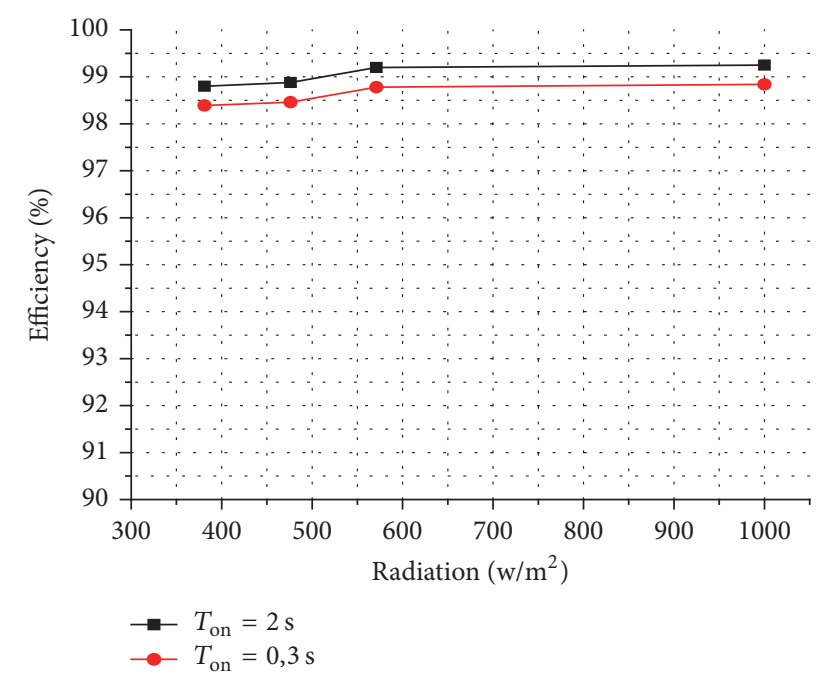

FIgURE 12: Proposed MPPT technique efficiency as a function of irradiation when the reference power signal $\left(P_{\text {ref }}\right)$ vary between $-15 \mathrm{~V}$ and $15 \mathrm{~V}$.

of the power device. This value is in general limited by maximum junction temperature in the active device.

In order to increase the efficiency of the proposed analog MPPT technique a bipolar $(+15 \mathrm{~V} /-15 \mathrm{~V}) P_{\text {ref }}$ signal is used. In fact, when the variation of $P_{\text {ref }}$ becomes equal to $30 \mathrm{~V}$, the relative error generated by the proposed MPPT technique, in order to detect the optimum power, decreases. Figure 12 shows the change of the MPPT technique's efficiency as a function of irradiation. We notice that the maximum efficiency reaches $99.3 \%$ at $1000 \mathrm{~W} / \mathrm{m}^{2}$. In literature [1921], the various classical $\mathrm{P} \& \mathrm{O}$ or conductance incremental algorithms yield MPPT efficiency between $95 \%$ and $98 \%$.

Beyond $T_{\text {on }}$ duration equal to $2 \mathrm{~s}$, the efficiency of the proposed technique tends to $99.5 \%$.

In the proposed analog MPPT technique, we obtained a good efficiency of the technique compared to the analog techniques proposed in literature $[22,23]$ (varying between $95 \%$ and $99.5 \%$ ). If we compare our technique to the best one, allowing a comparable efficiency, published in literature, we can find that the proposed technique uses a low number of discrete devices and only one multiplier circuit is used. The good technique efficiency associated with a low number of electronic functions can be promising and the integration of the proposed analog MPPT solution can offer an interest in IC circuit.

\section{Experimental Validation of the Proposed MPPT Technique}

For this purpose, the boost converter is realized, and the used semiconductor devices are the STGW30V60F N-channel IGBT Transistor and the STTA3006P Diode.

The realized analog MPPT circuit is shown in Figure 13.

A PV panels (JA SOLAR) generating a maximum power around $580 \mathrm{~W}$, at the temperature $25^{\circ} \mathrm{C}$ and irradiation of $1000 \mathrm{~W} / \mathrm{m}^{2}$, are used.

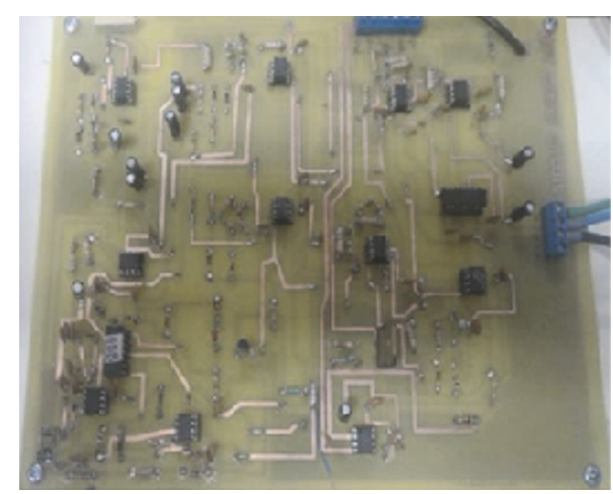

FIgURE 13: Photo of the realized analog PMMT control circuit.

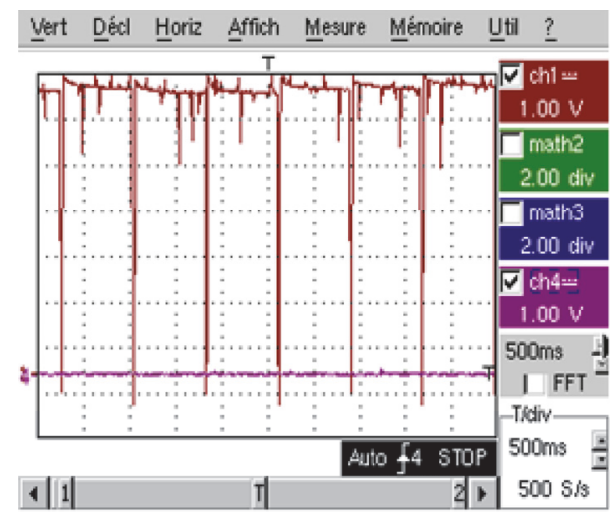

FIGURE 14: $P_{\text {real }}$ experimental curve for $T_{\text {on }}=800 \mathrm{~ms},\left(P_{\text {real }}\right.$ in brown, $1 \mathrm{~V}$ scale $=100 \mathrm{~W})$.

The open circuit voltage of the PV panels is equal to $105 \mathrm{~V}$.

We notice that, in the experimental waveform shown in Figure 14, the $T_{\text {on }}$ duration value of the $P_{\text {ref }}$ signal was chosen equal to $800 \mathrm{~ms}$ and $T_{\text {off }}$ duration equal to $40 \mathrm{~ms}$ in order to see the transient phenomena of the $P_{\text {real }}$ evolution in oscilloscope. In practice the value of $T_{\text {on }}$ can reach a higher value and $T_{\text {off }}$ a lower value in order to increase the efficiency of the tracking technique.

\section{Conclusion}

A new technique to track the maximum power point operation using analog MPPT controller is proposed in this paper. The proposed MPPT control strategy has the ability of fast tracking of the MPP for PV systems. It uses DCDC boost converter. Through simulation by Proteus-ISIS and experiments, the accuracy and feasibility of the proposed method were validated. The idea proposed showed its accuracy to detect the optimal generated power by the PV panels. An improvement of the technique efficiency, by using a bipolar voltage of the reference $P_{\text {ref }}$ signal, was registered. The efficiency of the analog MPPT technique reaches values higher than $99 \%$. 


\section{Conflicts of Interest}

The authors declare that there are no conflicts of interest regarding the publication of this paper.

\section{Acknowledgments}

This paper contains the results and funding of a research project that is funded by King Abdulaziz City for Science and Technology (KACST) Grant no. 35-130.

\section{References}

[1] T. Mrabti, M. El Ouariachi, R. Malek et al., "Design, realization and optimization of a photovoltaic system equipped with analog maximum power point tracking (MPPT) command and detection circuit of the dysfunction and convergence the system (CDCS)," (IJPS) International Journal of Physical Sciences, vol. 6, no. 35, pp. 7865-7888, 23 December 2011.

[2] D. Dondi, A. Bertacchini, D. Brunelli, L. Larcher, and L. Benini, "Modeling and optimization of a solar energy harvester system for self-powered wireless sensor networks," IEEE Transactions on Industrial Electronics, vol. 55, no. 7, pp. 2759-2766, July 2008.

[3] Y.-H. Liu, Z.-Z. Yang, S.-C. Wang, and J.-W. Huang, "A novel analog MPPT technique for low power photovoltaic systems," in Proceedings of the 2011 IEEE Region 10 Conference: Trends and Development in Converging Technology Towards 2020, TENCON 2011, pp. 833-837, idn, November 2011.

[4] Y.-H. Chang and C.-Y. Chang, "A Maxi mum Power Point Tracking of PV System by Scaling Fuzzy Control," in Proceedings of the presented at International Multi Conference of Engineers and Computer Scientists, Hong Kong, 2010.

[5] S. Mekhilef, "Performance of grid connected inverter with maximum power point tracker and power factor control," International Journal of Power Electronics, vol. 1, no. 1, pp. 49-62, 2008.

[6] S. Chin, J. Gadson, and K. Nordstrom, "Maximum Power Point Tracker," Tufts University Depart ment of Electrical Engineering and Computer Science, pp. 1-66, 2003.

[7] C. S. Lee, "A Residential DC Distribution System with Photovoltaic Array Integration," vol. Degree of Honors Baccalaureate of Science in Electrical and Electronics Engineering, p. 38, 2008.

[8] T. P. Nguyen, "Solar Panel Maximum Power Point Tracker," Department of Computer Science and Electrical Engineering: University of Queensland, p. 64, 2001.

[9] R. Faranda and S. Leva, "Energy Comparison of MPPT techniques for PV Systems," WSES Transaction on Power Systems, vol. 3, p. 446455, 2008.

[10] B. S, N. Thansoe, R. G, K. A. S, and L. C. J, "The Study and Evaluation of Maximum Power Point Tracking Systems," International Conference on Energy and Environment 2006 (ICEE 2006), pp. 17-22, 2006.

[11] T. Esram and P. L. Chapman, "Comparison of photovoltaic array maximum power point tracking techniques," in 9. Urbana, IEEE Transactions on Energy Conversion, vol. 22, no. 2, pp. 439-449, 2007.

[12] R. Karthikeyan and Dr. A. k. Parvathy, "Study Of Pv Panels And Analysis Of Various Mppt Techniques," (Jatit) Journal Of Theoretical And Applied Information Technology, vol. 68, no. 2, 20 October 2014.
[13] T. Esram, J. W. Kimball, P. T. Krein, P. L. Chapman, and P. Midya, "Dynamic maximum power point tracking of photovoltaic arrays using ripple correlation control," IEEE Transactions on Power Electronics, vol. 21, no. 5, pp. 1282-1290, September 2006.

[14] N. Mhiri, K. Ammous, A. Alahdal, H. Ghulman, and A. Ammous, "Design of a new analog circuit for Maximum Power Point tracking of photovoltaic panels," in Proceedings of the 7th International Renewable Energy Congress, IREC 2016, March 2016.

[15] M. Orabi, F. Hilmy, A. Shawky, J. A. Abu Qahouq, E.-S. Hasaneen, and E. Gomaa, "On-chip integrated power management MPPT controller utilizing cell-level architecture for PV solar system," Solar Energy, vol. 117, pp. 10-28, 2015.

[16] J. M. Enrique, J. M. Andujar, and M. A. Bohoérquez, "A reliable, fast and low cost maximum power point tracker for photovoltaic applications," Solar Energy, vol. 84, no. 1, pp. 79-89, 2010.

[17] G. El-Saady, I. El-NobiA, and M. EL-Hendawi, "Simulated Annealing Modeling and Analog MPPT Simulation for Standalone Photovoltaic Arrays," (IJPEE) International Journal on Power Engineering and Energy, vol. 4, no. 1, pp. 353-360, 2013.

[18] http://www.jasolar.com/uploads/JAP6\%2060\%20245-265\% 203BB.pdf.

[19] C.-Y. Hsieh, C.-Y. Yang, F.-K. Feng, and K.-H. Chen, "A photovoltaic system with an analog maximum power point tracking technique for $97.3 \%$ high effectiveness," in Proceedings of the 36th European Solid State Circuits Conference, ESSCIRC 2010, pp. 230-233, September 2010.

[20] http://www.labcenter.com/index.cfm.

[21] M. Azab, "A new maximum power point tracking for photovoltaic systems," (IJEEE) International Journal of Electrical and Electronics Engineering, 2009.

[22] S.-K. Ji, D.-H. Jang, and S.-S. Hong, "Analog control algorithm for maximum power trackers employed in photovoltaic applications," (JPE) Journal of Power Electronics, vol. 12, no. 3, pp. 503508, May 2012.

[23] M. El Ouariachi, T. Mrabti, B. Tidhaf, Ka. Kassmi, and K. Kassmi, "Regulation of the electric power provided by the panels of the photovoltaic systems," (IJPS) International Journal of Physical Sciences, vol. 4, no. 5, pp. 294-309, May 2009. 


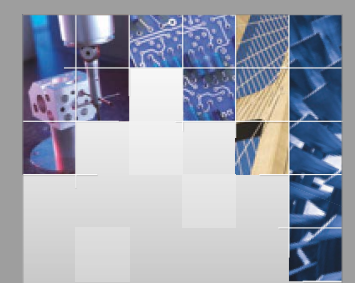

\section{Enfincering}
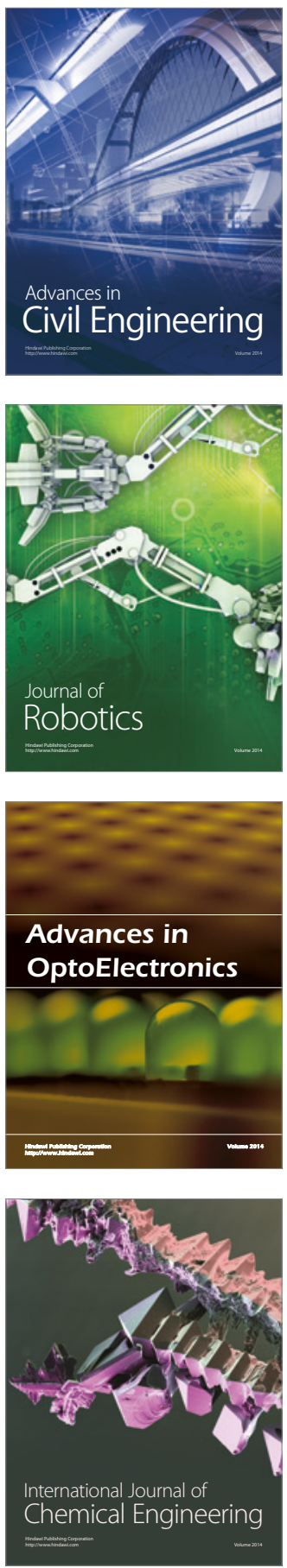

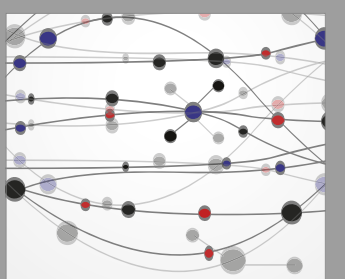

The Scientific World Journal

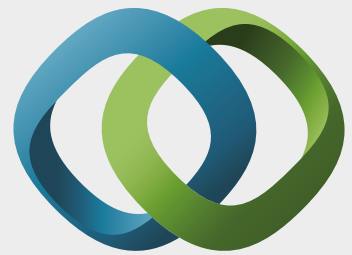

\section{Hindawi}

Submit your manuscripts at

https://www.hindawi.com
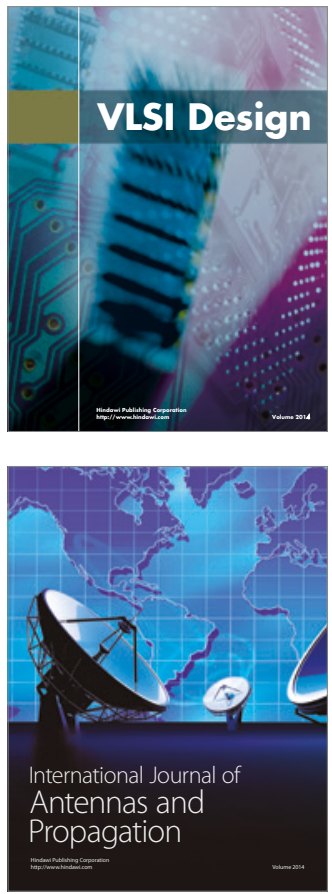

\section{Rotating}

Machinery
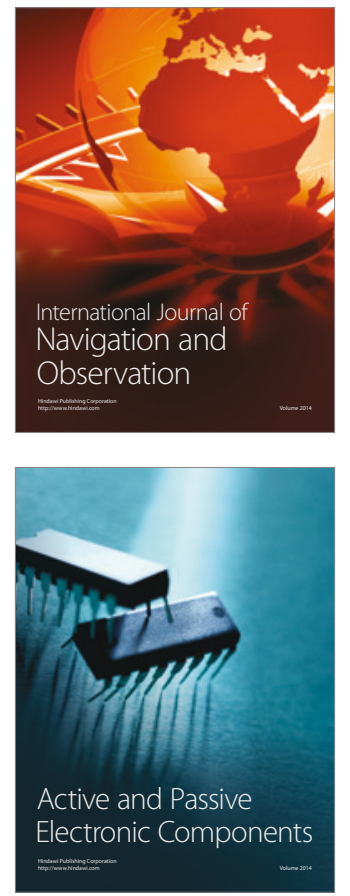
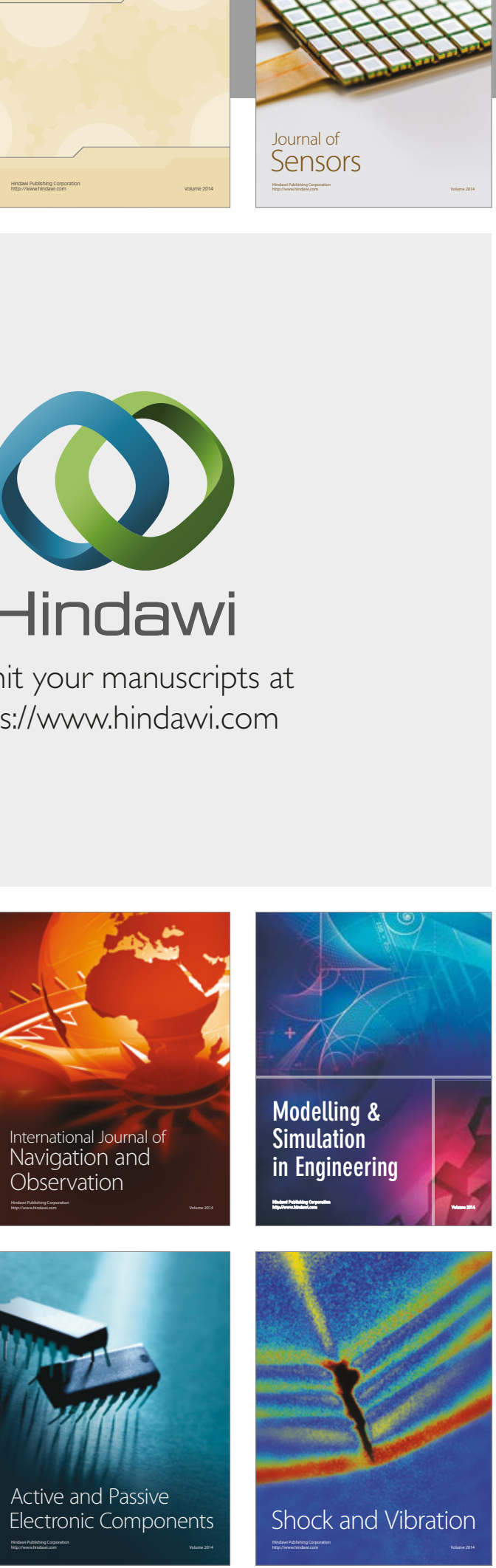
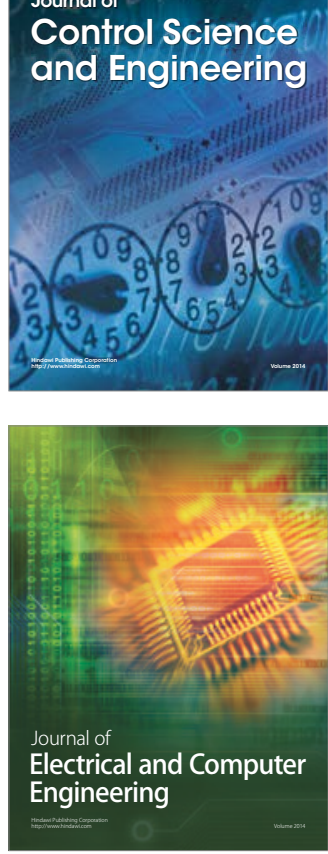

Distributed

Journal of

Control Science

and Engineering
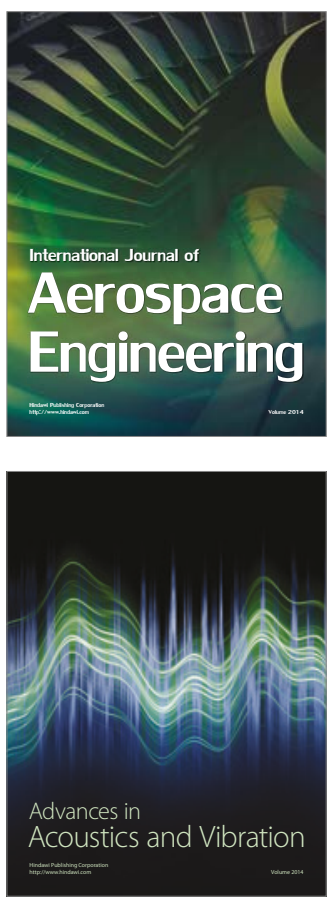

Sensor Networks 